\title{
СОРБЦИЯ АНТОЦИАНОВ НА БЕНТОНИТОВОЙ ГЛИНЕ
}

\author{
(C) 2020 г. В. И. Дейнека ${ }^{a, *}$, А. Г. Доронин ${ }^{a}$, Е. Ю. Олейниц ${ }^{a}$ И. П. Блинова ${ }^{a}$, \\ Л. А. Дейнека ${ }^{a}$, А. Н. Чулков ${ }^{b}$ \\ ${ }^{a}$ Белгородский государственный национальный исследовательский университет, 308015, г. Белгород, Россия \\ ${ }^{b}$ Белгородский филиал “Центр оценки качества зерна и продуктов его переработки”, 308027, Белгород, Россия \\ *e-mail: deineka@bsu.edu.ru \\ Поступила в редакцию 03.07.2019 г. \\ После доработки 03.07.2019 г. \\ Принята к публикации 15.10.2019 г.
}

\begin{abstract}
Определены закономерности статистической сорбции антоцианов на бентонитовой глине. Установлено, что метод, применимый в статическом варианте, является альтернативой методу динамической твердофазной очистки на концентрирующих патронах ДИАПАК С18. Предложен способ оценки относительной сорбционной способности антоцианов различного строения на бентонитовой глине в условиях выполнения уравнения Ленгмюра. Показано, что сорбционная способность уменьшается при усложнении строения гликозидных радикалов (от пентозида к гексозиду и далее - к ди- и три-сахаридам). Ацилирование гликозидных радикалов малоновой кислотой мало сказывается на сорбционной способности, в то время, как ацилирование замещенными коричными кислотами способствует сорбции.
\end{abstract}

Ключевые слова: антоцианы, твердофазная экстракция, бентонитовые глины, обращенно-фазовая ВЭЖХ, сорбционная способность

DOI: $10.31857 /$ S0044453720060072

Антоцианы в растительных объектах обычно синтезируются в виде сложного набора соединений различного строения, поэтому анализ таких смесей всегда представляет собой сложную задачу. Отличительная особенность антоцианов состоит в существовании нескольких $\mathrm{pH}$-зависимых форм [1]. Окрашенная в красные цвета с зависящими от строения молекулы оттенками флавилиевая форма (схема) позволяет детектировать эти соединения при их разделении в условиях обращенно-фазовой хроматографии с использованием спектрофотометрического детектора с длиной волны, $\lambda$, в диапазоне 500-530 нм при наличии большого числа неокрашенных сопутствующих экстрактивных веществ.<smiles></smiles>

Строение флавилиевой формы антоцианов
Но невидимые при этом вещества могут сделать невозможным определение некоторых параметров пиков антоцианов, например, при массспектрометрическом детектировании из-за наложения сигналов. Анализ особенно усложняется, если концентрации сопутствующих веществ превосходят концентрацию антоцианов в исследуемых объектах. Используемая частичная очистка методом твердофазной экстракции на обращенно-фазовых сорбентах в этом отношении становится не эффективной. Альтернатива этим сорбентам - неорганические ионообменники, например, бентонитовые глины [2-6].

Цель настоящей работы - оценка сорбционной активности глин по отношению к антоцианам различного строения из сложных смесей, синтезируемых в реальных растительных источниках.

\section{ЭКСПЕРИМЕНТАЛЬНАЯ ЧАСТЬ}

В работе использовали экстракты антоцианов из коллекции лаборатории, полученные настаиванием растительных материалов в 0.1 М водном растворе соляной кислоты при комнатной температуре вне доступа прямого солнечного света. Экстракты хранили в морозильной камере в пла- 
стиковой посуде. Для очистки использовали два метода.

Метод динамической твердофазной экстракции. Насадочные картриджи (патроны) ДИАПАК С18, активировали пропусканием 5 мл ацетона. Затем кондиционировали пропусканием $10-15$ мл $0.1 \mathrm{M}$ водного раствора $\mathrm{HCl}$. Исходные жидкие экстракты пропускали через патроны до появления первых окрашенных порций элюата. Патрон промывали небольшим объемом (0.5-1.0 мл) $0.1 \mathrm{M}$ водного раствора $\mathrm{HCl}$. Антоцианы реэкстрагировали раствором, содержащим 30 об. \% ацетонитрила и 30 об. \% муравьиной кислоты в воде до обесцвечивания сорбента патрона. Реэкстракт разбавляли дистиллированной водой в три раза для хранения и последующего ВЭЖХ анализа. Экспериментально установлено, что такая очистка (не являющаяся полной) экстракта обеспечивает длительное использование хроматографической колонки (в течение нескольких лет).

Метод статической сорбции. К заданному объему экстракта добавляли экспериментально определяемую навеску специально подготовленной бентонитовой глины, БГ. Смесь встряхивали на механическом встряхивателе в течение 40 мин. Затем полученную смесь центрифугировали, отделяя маточный раствор от глины. При необходимости сорбцию из маточного раствора повторяли, используя новую навеску глины. Далее образцы глины объединяли и добавляли заданную порцию экстрагента (30 об. \% ацетонитрила и 30 об. \% муравьиной кислоты в воде), встряхивали 40 мин и раствор отделяли центрифугированием. Обычно использовали повторную реэкстракцию. Объединенные экстракты разбавляли в 3 раза перед хранением и ВЭЖХ-определением антоцианов.

Бентонитовую глину марки Бентакон [5] (содержащую по данным производителя более $80 \%$ монтмориллонита) отмывали от добавок карбоната натрия в порциях $0.1 \mathrm{M}$ раствора $\mathrm{HCl}$. Высушивали в лиофильной сушке после замораживания, получая мелкодисперсный порошок, не требующий дальнейшего измельчения (в отличие от порошка, полученного высушиванием в сушильном шкафу).

Суммарное содержание антоцианов оценивали упрощенным спектрофотометрическим методом (без дифференциального подхода) - по величине абсорбции при $\mathrm{pH} 1$.

Разделение антоцианов в растворах (после твердофазной очистки) осуществляли на оборудовании Agilent 1200 Infinity с диодно-матричным детектором. Хроматограммы записывали при 520 нм. В работе использовали хроматографическую колонку: $150 \times 4.6$ мм Symmetry C18 (3.5 мКм); температура термостата колонок $40^{\circ} \mathrm{C}$. Мертвое время определяли по щавелевой кислоте. Разделение осуществляли в градиентном ре- жиме, используя две подвижные фазы, содержащие A: 10 об. \% муравьиной кислоты и 6 об. \% ацетонитрила в воде и Б: 10 об. \% муравьиной кислоты и 20 об. \% ацетонитрила в воде при расходе подвижной фазы 0.8 мл/мин. Градиентный режим: 0 мин - 0\% Б, 20 мин - 100\% Б, 30 мин $100 \%$ Б, 31 мин - 0\% Б и 40 мин - 0\% Б.

Хроматограммы регистрировали и обрабатывали программой ChemStation.

Для сокращенного обозначения антоцианов в работе использованы буквенные обозначения: $\mathrm{Dp}$ - дельфинидин $\left(3,5,7,3^{\prime}, 4^{\prime}, 5^{\prime}\right.$-гексагидроксофлавилий $),$ Су - цианидин $\left(3,5,7,3^{\prime}, 4^{\prime}\right.$-пентагидроксофлавилий $), \mathrm{Pt}$ - петунидин $\left(3,5,7,3^{\prime}, 4^{\prime}-\right.$-пентагидроксо-5'-метоксифлавилий), $\mathrm{Pn}$ - пеонидин (3,5,7,4'-тетрагидроксо-3'-метоксифлавилий), $\mathrm{Mv}$ - мальвидин (3,5,7,4'-тетрагидроксо-3',5'-диметоксифлавилий), см. рис. 1.

\section{ОБСУЖДЕНИЕ РЕЗУЛЬТАТОВ}

Сорбционный материал пригоден для пробоподготовки, если сорбция аналитов обратима и отсутствует каталитическая активность сорбента по отношению к этим аналитам.

Для проверки обратимости сорбции был поставлен эксперимент, в котором использовали два экстракта антоцианов с различным видовым составом - экстракты плодов черной смородины (А) и плодов аронии Мичурина (Б). В случае А экстракт содержит в качестве основных компонентов четыре антоциана: 3-глюкозиды и 3-рутинозиды цианидина и дельфинидина [7], а в случае Б основные компоненты - цианидин-3-галактозид и цианидин-3-арабинозид с небольшими примесями цианидин-3-глюкозида и цианидин3-ксилозида [8]. Разделение этих веществ при их совместном присутствии легко осуществляется в условиях обращенно-фазовой хроматографии, рис. 1.

Вначале к указанным индивидуальным экстрактам (при примерно равной суммарной концентрации антоцианов в них) добавляли равные навески глины и смесь выдерживали при встряхивании в течение 40 мин. Соотношение экстракт-глина подбирали с таким расчетом, чтобы в обоих случаях было сорбировано около $50 \%$ исходных антоцианов.

Полученные смеси разделяли центрифугированием и к отделенным от растворов двум образцам глины (с сорбированными антоцианами) добавляли противоположные экстракты, выдерживая смеси в течение тех же 40 мин с последующим анализом маточного раствора. Полученные результаты представлены на рис. 1. Так, с глины, на которой были вначале сорбированы антоцианы черной смородины, при ее смешивании с экстрактом аронии в растворе обнаружены антоциа- 


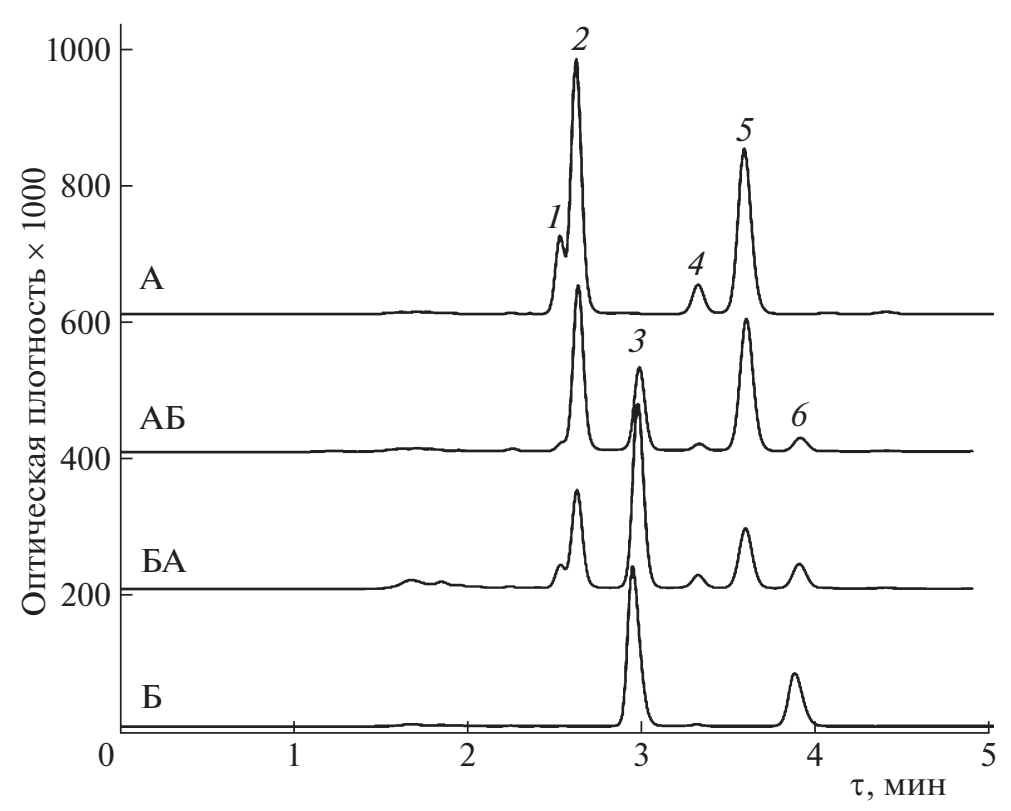

Рис. 1. Разделение антоцианов плодов черной смородины (а) и аронии Мичурина (б). Колонка $4.6 \times 150 \mathrm{Symmetry} \mathrm{C18,}$ 3.5 мкм; подвижная фаза: 10 об. \% муравьиной кислоты и 10 об. \% ацетонитрила в воде, 0.8 мл/мин. Температура термостата колонки $40^{\circ} \mathrm{C}$. Составы маточных растворов над глинами после сорбции антоцианов - описание АБ и БА см. в тексте. Антоцианы: 1 - Dp3Glu, 2 - Dp3Rut, 3-Cy3Gala, 4-Cy-3-Glu, 5 - Cy3Rut.

ны первого растительного материала и наоборот, а антоцианы плодов аронии перешли частично в экстракт черной смородины во втором случае, что подтверждает обратимость сорбции антоцианов на монтмориллонитовых глинах.

Тест на каталитическую активность выполнить достаточно сложно, поскольку в случае БГ могут наблюдаться потери антоцианов за счет частичной интеркалации в межпакетное пространство [9], а в случае обращенно-фазовых сорбентов - из-за их частичного проникновения в галерейные поры [10]. Поэтому в настоящей работе использовали сопоставление соотношения между видами антоцианов в образцах, полученных при двух способах очистки. Экстракт плодов черники был выбран для исследования, поскольку содержит 3-моногликозиды (3-галактозиды, 3-глюкозиды и 3-арабинозиды) пяти из шести основных антоцианидинов (дельфинидина, цианидина, петунидина, пеонидина и мальвидина) в сопоставимых количествах, рис. 2.

Полученные результаты оказались довольно близкими, табл. 1, но не эквивалентными. Так, при очистке на БГ концентрация производных дельфинидина (наиболее гидрофильных из компонентов экстракта) оказалась несколько меньшей по сравнению с продуктом, полученным при твердофазной экстракции на насадочных картриджах ДИАПАК C18 (патронах С18). Это может быть следствием принципиальных различий между двумя использованными методами. Действительно, в случае патронов С18 осуществляется полная сорбция антоцианов экстракта (до проскока окрашенных фракций) с последующей реэкстракцией до полного обесцвечивания сорбента в динамическом режиме. Но динамический режим невозможен при использовании в качестве copбента БГ, - сорбцию и десорбцию осуществляли в статическом режиме с отделением БГ центрифугированием, при этом добиться полного обесцвечивания БГ трудно.

Найденная особенность состава антоцианов после твердофазной очистки на БГ указывает на необходимость установления зависимости сорбции антоцианов от их строения, на что указывалось в работе [5]. При этом основная проблема при количественном определении антоцианов, отсутствие надежных данных о влиянии строения вещества на коэффициенты молярного погашения индивидуальных видов антоцианов. Но эта проблема исключается при использовании в качестве измеряемого параметра безразмерной степени адсорбции индивидуальных антоцианов, $\alpha(A)$, рассчитываемой по формуле:

$$
\alpha(A)=\frac{S_{0}(A)-S_{i}(A)}{S_{0}(A)},
$$

где $S_{0}(A)$ и $S_{i}(A)$ - площади пиков на хроматограммах экстрактов или их смесей до сорбции и после сорбции соответственно.

Для исключения влияния сопутствующих экстрактивных веществ в настоящей работе определяли относительные характеристики сорбции различных типов антоцианов из специально по- 


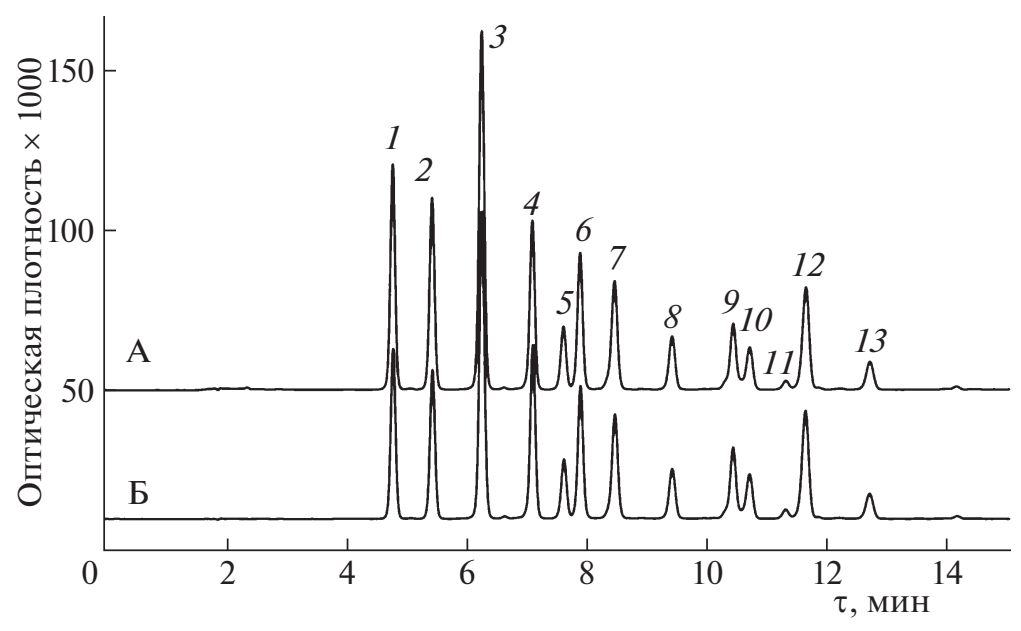

Рис. 2. Разделение антоцианов плодов черники после очистки на патронах С18 (А) и на бентонитовой глине (Б). Хроматографические условия см. рис. 1, нумерацию пиков см. табл. 1.

добранных смесей экстрактов различных объектов, которые должны содержать антоциан, используемый в качестве образца сравнения. При этом в качестве вешества сравнения использовали цианидин-3-гексозид (3-глюкозид или 3-галактозид, имеющие одинаковые размеры). Склонность антоцианов к сорбции определяли по изменению оптической плотности экстрактов после добавления глины (используя спектрофотометрический метод) с последующим определением доли видов антоцианов в смеси (используя разделение в условиях обращенно-фазовой ВЭЖХ при расчетах по методу нормировки). Для определения параметра, пропорционального сорбционной способности различных индивидуальных антоцианов из сложных многокомпонентных смесей, воспользуемся уравнением Ленгмюра, применимым для сорбции антоцианов на БГ по данным [5]:

$$
A(A)=A_{\max } \frac{b(A)[A]}{1+\sum b(i)[i]},
$$

где $A(A)$ - количественная характеристика величины сорбции компонента $A$, моль/г, $b(A)-$ константа адсорбционного равновесия, $[A]$ - равновесная концентрация компонента $A$, моль/л, $i-$ другие компоненты смеси антоцианов.

Таблица 1. Сопоставление антоцианового состава экстрактов после частичной очистки на двух типах сорбентов

\begin{tabular}{|c|c|c|c|c|c|}
\hline \multirow[t]{2}{*}{ № } & \multirow[t]{2}{*}{ Вид антоциана } & \multirow[t]{2}{*}{$t_{\mathrm{R}}$, МИн } & \multicolumn{2}{|c|}{$\begin{array}{c}\text { Относительная доля веществ } \\
\text { по площадям пиков, \% }\end{array}$} & \multirow{2}{*}{$\begin{array}{c}\text { Различие } \\
\text { в составе, \% }\end{array}$} \\
\hline & & & глина & $\mathrm{C} 18$ & \\
\hline 1 & Dp3Gala & 4.79 & 10.5 & 12.6 & -16.7 \\
\hline 2 & Dp3Glu & 5.44 & 9.6 & 11.3 & -15.0 \\
\hline 3 & Dp3Ara + Cy3Gala & 6.26 & 20.4 & 21.8 & -6.4 \\
\hline 4 & Cy3Glu & 7.10 & 11.5 & 10.1 & 13.9 \\
\hline 5 & Pt3Gala & 7.62 & 4.2 & 4.1 & 2.4 \\
\hline 6 & Cy3Ara & 7.89 & 9.0 & 8.4 & 7.1 \\
\hline 7 & Pt3Glu & 8.46 & 8.1 & 7.9 & 2.5 \\
\hline 8 & Pt3Ara + Pn3Gala & 9.41 & 4.0 & 3.9 & 2.6 \\
\hline 9 & Pn3Glu & 10.42 & 6.0 & 5.3 & 13.2 \\
\hline 10 & Mv3Gala & 10.69 & 3.7 & 3.2 & 15.6 \\
\hline 11 & Pn3Ara & 11.29 & 0.8 & 0.7 & 14.3 \\
\hline 12 & Mv3Glu & 11.82 & 9.5 & 8.3 & 14.5 \\
\hline 13 & Mv3Ara & 12.68 & 2.6 & 2.4 & 8.3 \\
\hline
\end{tabular}

Обозначения: № - номер пика на рис. 2. 
В таком случае степень сорбции компонента $A$ может быть определена по уравнению:

$$
\alpha(A)=\frac{A(A) m}{A(A) m+[A] V},
$$

или

$$
\frac{1}{\alpha(A)}=1+\frac{[A] V}{A(A) m}
$$

где $m$ - масса сорбента, г, $V$ - объем экстракта, л (при пренебрежении изменением объема экстракта в результате сорбции).

Подставляя выражение (2) в уравнение (3), получаем:

$$
\frac{1}{\alpha(A)}-1=\frac{V\left(1+\sum b(i)[i]\right)}{A_{m} b(A) m} .
$$

Теперь можно получить простую формулу для определения количественного соотношения между сорбционной способностью двух веществ, $A$ и $B$, сорбируемых из смеси, через показатель сорбционной (ПСА) активности, равный отношению констант сорбционного равновесия:

$$
\left(\frac{1}{\alpha(A)}-1\right) /\left(\frac{1}{\alpha(B)}-1\right)=\frac{b(B)}{b(A)} \text {. }
$$

На примере смеси 1 , состоящей из трех антоцианов, цианидин-3,5-диглюкозида (Су3,5diGlu), цианидин-3-галактозида (Cy3Gala) и цианидин3-арабинозида (Су3Ara), по формуле (6) получены согласующиеся между собой ПСА в широком диапазоне суммарной сорбции антоцианов (24, 52 и 75\%), табл. 2. Это подтверждает правомочность использования уравнения Ленгмюра и предложенного подхода для описания сорбции антоцианов на БГ. Из полученных результатов следует, что переход от гексозида к пентозиду (от Cy3Gala к Су3Ara) приводит к росту ПСА почти в полтора раза, а переход к дигексозиду - к снижению ПСА почти в три раза. Следовательно, можно принять гипотезу о том, что ПСА уменьшается с ростом размера гликозидного заместителя. Действительно, на еще одном примере сложной смеси было установлено, что ПСА цианидин-3-глюкозида и цианидин-3-галактозида очень близки между собой, что подтверждает главенствующую роль размерного фактора.

Следующая смесь включала цианидин-3-глюкозид (Cy3Glu), цианидин-3-рутинозид (Cy3Rut) и петунидин-3-(nара-кумароилрутинозид)-5глюкозид (Pt3(CoumRut)5Glu). Для нее были получены также согласующиеся между собой ПСА при трех различных степенях сорбции результаты. Из них следует, что сорбционная способность антоцианов снижается примерно в 4 раза при укрупнении гликозидного заместителя в положении 3 до рутинозидного (прибавление рамно-

\begin{tabular}{|c|c|c|c|c|c|}
\hline № & Антоциан & \multicolumn{3}{|c|}{$b(i) / b\left(\mathrm{Cy} 3 \mathrm{Hex}^{*}\right)$} & $\begin{array}{c}\text { Среднее } \\
\text { значение }\end{array}$ \\
\hline \multicolumn{6}{|c|}{ Смесь № 1} \\
\hline 1 & Cy3,5diGlu & 0.31 & 0.34 & 0.33 & 0.33 \\
\hline 2 & Cy3Gala & 1 & 1 & 1 & 1 \\
\hline 3 & Cy3Ara & 1.52 & 1.46 & 1.32 & 1.43 \\
\hline$\omega^{* *}, \%$ & & 12.7 & 9.6 & 4.2 & \\
\hline \multicolumn{6}{|c|}{ Смесь № 2} \\
\hline 1 & Cy3Glu & 1 & 1 & 1 & 1 \\
\hline 2 & Cy3Rut & 0.26 & 0.25 & 0.27 & 0.26 \\
\hline 3 & $\begin{array}{l}\text { Pt3(Coum- } \\
\text { Rut)5Glu }\end{array}$ & 0.94 & 0.89 & 0.7 & 0.84 \\
\hline$\omega^{* *}, \%$ & & 12.7 & 6.4 & 3.5 & \\
\hline \multicolumn{6}{|c|}{ Смесь № 4} \\
\hline 1 & Cy3Glu & 1 & 1 & 1 & 1 \\
\hline 2 & Cy3Rut & 0.19 & 0.19 & 0.21 & 0.20 \\
\hline 3 & Cy3Mal*Glu & 1.08 & 1.09 & 1.15 & 1.11 \\
\hline 4 & Cy3MalGlu & 0.91 & 0.88 & 1.08 & 0.96 \\
\hline 5 & Cy3diMalGlu & 1.27 & 1.35 & 1.50 & 1.37 \\
\hline$\omega^{* *}, \%$ & & 11.6 & 6.6 & 3.7 & \\
\hline
\end{tabular}

Таблица 2. Сопоставление относительной сорбционной способности антоцианов на бентонитовой глине из специальных смесей

* Гексозид (глюкозид или галактозид).

** Степень заполнения поверхности.

зильного радикала к глюкозидному). В то же время для Pt3(CoumRut)5Glu ПCA оказалась близкой к ПСA Cy3Glu, несмотря на существенное усложнение структуры заместителей. Впрочем, ассоциация кумароильного радикала с флавилиевой основой [11] может быть причиной нивелирования размерного фактора.

Для смеси, содержащей еще более удлиненный (тригликозидный) заместитель в положении 3 агликона - для цианидин-3-(2"-глюкозилрутинозида) при $10 \%$-ном уровне сорбции найден относительный (относительно Cy3Glu) показатель сорбционной активности лишь 0.020 (т.е. в 50 раз ниже аналогичного свойства вещества сравнения). Отметим, что при этом для Су3Rut этот показатель составил 0.23 , что согласуется с данными, полученными для смеси 2.

При исследовании влияния ацилирования на сорбционную способность антоцианов были исследованы смеси, содержащие Cy3Glu, ацилированный по различным положениям [12] (и даже диацилированный) малоновой кислотой, табл. 2. Оказалось, что такой тип ацилирования мало влияет на ПСА, а некоторые тенденции к повышению этого показателя могут быть связаны со специфическим строением антоцианов, для ко- 
торых возможно образование внутримолекулярных водородных связей.

Результаты исследования очистки антоцианов от сопутствующих примесей при сорбции на БГ показали, что они, действительно, в значительной степени, хотя и не всегда полностью, могут быть отделены от антоцианов.

\section{СПИСОК ЛИТЕРАТУРЫ}

1. Lapidot T., Harel S., Akiri B. et al. // J. Agric. Food Chem. 1999. V. 47. P. 67.

2. Krupskaya V.V., Zakusin S.V., Tyupina E.A. et al. // Minerals. 2017. V. 7. P. 49; https://doi.org/10.3390/min7040049

3. Charlet L., Tournassat C. // Aquatic Geochemistry. 2005. V. 11. P. 115.

4. Mcatee J.L., Jr. // Clays and Clay Minerals (Proceedings of the Ninth National Conference on Clays and Clay Minerals, 1962). Pergamon press. 2013. P. 444.
5. Дейнека Л.А., Чулков А.Н., Дейнека В.И. // Журн. прикл. химии. 2009. № 5. С. 742.

6. Soldatkina L., Novotna V. // Adsorption Sci. Technol. 2017. V. 35. P. 866.

7. Дейнека Л.А., Шапошник Е.И., Гостищев Д.А. и др. // Сорбц. хром. процессы. 2009. Т. 9. Вып. 4. С. 529.

8. Дейнека Л.А., Блинова И.П., Чулков А.Н. и др. // Научные ведомости БелГУ. Серия Медицина. Фармация. 2012. № 10 (129). Вып. 18/2. С. 60.

9. Kohno Y., ShujiIkoma K., Yoda K. et al. // Appl. Clay Sci. 2009. V. 42. P. 519

10. Дейнека В.И., Дейнека Л.А., Сидоров А.Н. и др. // Физикохимия поверхности и защита материалов. 2017. T. 53. № 3. С. 262.

11. Дейнека В.И., Кульченко Я.Ю., Дейнека Л.А. // Журн. физ. химии. 2019. Т. 93. № 3. С. 459.

12. Дейнека В.И., Сидоров А.Н., Дейнека Л.А. // Журн. аналит. химии. 2016. Т. 71. № 11. С. 1203 